\title{
Resistencias en la poesía peruana de los 80: colonialismo interno, posmodernidad/neoliberalismo y violencia política
}

\section{Paolo de Lima ${ }^{1}$}

Universidad Científica del Sur

\section{RESUMEN}

Este ensayo es una lectura de dos agrupaciones de poetas peruanos durante los años 80 (Tres Tristes Tigres y Kloaka) desde aspectos relacionados con discursos políticos, sociales y culturales tanto internacionales como propios del país que, imbricados, permiten apreciar la fragmentación del sujeto poético en sus poemas, y el protagonismo y la hegemonización que este adquiere en la poesía peruana de dicho periodo.

\section{PALABRAS CLAVE}

Poetas peruanos del 80 , violencia política, colonialismo interno, posmodernidad, neoliberalismo.

\begin{abstract}
This essay examines two groups of Peruvian poets during the 1980s (Three Sad Tigers and Kloaka) focusing on the political, social and cultural discourses, both national and international, that overlapped with the fragmentation of the poetic subject in their poems. The essay also analyzes the central and hegemonic role that the fragmented poetic subject acquired in the Peruvian poetry of this period.
\end{abstract}

\section{KEY WORDS}

Peruvian poets of the 80 s, political violence, internal colonialism, postmodernity, neoliberalism.

\footnotetext{
Doctor en Literatura por la Universidad de Ottawa, Canadá. Ha publicado los poemarios Cansancio (Filadelfia, 1995 y Lima, 1998), Mundo arcano (Lima, 2002) y Silenciosa algarabía (Lima, 2009). Ha publicado y/o realizado lecturas de sus poemas, ensayos y conferencias en El Paso, Austin, Columbus, Virginia, Boston (Estados Unidos), Ciudad Juárez (México), La Habana (Cuba), Sevilla, Madrid (España), Santiago (Chile), Río de Janeiro (Brasil), Ottawa, Montreal, Toronto (Canadá) y en diferentes ciudades del Perú. Actualmente es profesor de Literatura en Lima, en la Universidad Científica del Sur y en el programa de doctorado de la Universidad Nacional Mayor de San Marcos.
} 
Durante la primera mitad de la década de 1980, tanto los Tres Tristes Tigres (1980-1981) de la Universidad Católica (Raúl Mendizábal, Eduardo Chirinos, José Antonio Mazzotti) y los autores de Kloaka (1982-1984) de la Universidad de San Marcos (Domingo de Ramos, Róger Santiváñez, Dalmacia Ruiz-Rosas) recelaban ya de los primeros «aires neoliberales» en el contexto de la guerra interna peruana. Es allí donde radica el sentido de «novedad» y la importancia de ambos grupos de jóvenes poetas en el plano cultural y político. Ese estado de desconcierto, de pérdida de referentes políticos que reconstituyeran la sociabilidad democrática, explica los «palos de ciego» (desesperación, violencia verbal, pérdida de la palabra para hacer solo un balbuceo o un grito) de muchos de sus poemas.

En el Perú, los «aires neoliberales» ya se venían anunciando desde la segunda fase del gobierno militar, a mediados de la década de1970. Para 1992, con el inicio de la dictadura de Alberto Fujimori, y como señala José Matos Mar, se «afianzó la formación del Estado neoliberal» (125). Es decir, la apertura neoliberal empezó a sentirse desde el desmantelamiento de las reformas nacionalistas de la primera fase del gobierno militar (19681975) por los generales de la segunda fase (1975-1980). Con la subida al poder del civil Fernando Belaunde Terry en 1980, la política económica peruana se orientó hacia la apertura de las importaciones, las privatizaciones de empresas estatales y el fortalecimiento de la antigua oligarquía terrateniente reciclada en nueva burguesía comercial y exportadora. Esto significó, como digo, un desmantelamiento inicial y paulatino del Estado nacional y la consiguiente apertura (involuntaria o no) de narrativas alternas que desafiaban los antiguos esquemas homogeneizadores del propio Estado. En el caso de los poetas aquí nombrados, la alternatividad se manifestó a través de la exploración de las experiencias extremas (incluidas las experiencias políticas y experiencias con las drogas, el sexo, la búsqueda de mundos desconocidos, la irracionalidad, el imaginario mítico, etcétera) que derivaron en la formulación de subjetividades fragmentadas y de discursos esquizoides, claramente diferenciados de los de las retóricas conversacionales tradicionales de los 60 y 70.

No obstante, desde los años 60 se venía dando la emergencia de un debate a fondo sobre la modernidad; debate paralelo al «desarrollo de corrientes de pensamiento» (como la del neoliberalismo) que «desencadenarían el debate de la posmodernidad» (Orihuela 68). Antes que moderna, la peruana continúa siendo una sociedad neocolonial (aunque en un contexto de posmodernidad global), en el sentido de que es incapaz de borrar su legado colonial ni la estructura vertical que impide la entrada plena en la modernidad: un colonialismo interno; o sea, la herencia colonial subsistente en los vínculos entre el Estado criollo y el mundo andino. 
Es decir, el poder racista/etnicista que actúa desde un ineficiente Estadonación, sin embargo presente en el discurso moderno del Estado y del sujeto criollo. Todo ello estuvo al centro del enfrentamiento armado y de la aniquilación mayoritaria que sufrió el pueblo indígena durante la violencia política.

Ahora bien, en tanto fenómeno distinto del mero liberalismo clásico, a nivel global «el neoliberalismo», afirma el historiador inglés Perry Anderson, «nació después de la Segunda Guerra Mundial, en una región de Europa y de América del Norte donde imperaba el capitalismo. Fue una reacción teórica y política vehemente contra el Estado intervencionista y de bienestar. Su texto de origen es The Road to Serfdom, de Friedrich Hayek, escrito ya en 1944» («Balance del neoliberalismo» 18). Entre el 1 y el 10 de abril de 1947, Hayek convocó a 36 intelectuales (entre economistas, historiadores, filósofos, como Milton Friedman, Karl Popper y Ludwig von Mises) a una primera reunión de quienes compartían esta orientación ideológica. La reunión tuvo lugar en el Hôtel du Parc en la villa de Mont Pèlerin, cercana a la ciudad suiza de Montreux, lo que dio lugar a la Mont Pèlerin Society, que a partir de entonces se ha venido juntando cada dos años en diferentes lugares del mundo. Valga señalar que el libro de Hayek tuvo una inmediata y masiva difusión. En abril de 1945 Reader's Digest publicó una versión ligeramente condensada con un tiraje de 600 mil ejemplares. En 1950, la revista Look publicó una versión a modo de historieta, que posteriormente fue estratégicamente divulgada como folleto por la General Motors. Por su parte, para Michael Foucault (en un curso dictado en el Collège de France durante los primeros meses de 1979) el neoliberalismo germinó en la Escuela de Friburgo (Alemania) con los ordoliberales; específicamente en torno a la figura del economista Walter Eucken, quien vehiculiza dicha doctrina en la revista Ordo (que fundara en 1936), y en la cual llegaron a colaborar, entre otros, Karl Popper y el propio Friedrich Hayek, «un personaje muy importante», como señala Foucault, «cuya carrera, cuya trayectoria, tuvo en definitiva mucha importancia en la definición del neoliberalismo contemporáneo» (131).

En este punto, resulta apropiado entender el neoliberalismo como una categoría relacionada con la posmodernidad. A diferencia del debate norteamericano, que relaciona la posmodernidad (postmodernity) con el ámbito socioeconómico y el postmodernismo (postmodernism), con el cultural, en el debate hispanoamericano ambos términos implican una diferencia tajante. En la teoría norteamericana existe la tendencia a usar el término postmodernity en ciencias sociales como una «condición» que afectaría a todos los ámbitos de la vida social. Esto incluye el plano cultural, por supuesto, pero para sus propias manifestaciones como 
categoría de una nueva estética se usa el término de postmodernism. En Hispanoamérica, mientras que posmodernismo remite a la escuela literaria que en la segunda década del siglo XX buscó superar los aportes del modernismo de Rubén Darío, la posmodernidad se refiere tanto a la postmodernity como al postmodernism del debate norteamericano. Por eso, para referirme al caso peruano (lo cual puede ser extensivo a otros países), hablo de posmodernidad y neoliberalismo como categorías recíprocas.

De ahí que las expresiones artísticas o estéticas de la posmodernidad se constituyen a su vez en declaraciones políticas respecto del capitalismo multinacional, que en nuestro mundo de hoy se traduce en neoliberalismo. Numerosas de esas expresiones tienen amplia capacidad contestataria y estrategias múltiples para manifestarse; es decir, activan nuevas dinámicas de resistencia y oposición crítica. Esas expresiones se ofrecen tanto de manera abierta y frontal como de forma velada, oculta, entre líneas. En ese sentido específico, la posmodernidad es la expresión cultural y estética de la expansión del neoliberalismo en Latinoamérica. Por ello relaciono posmodernidad y neoliberalismo como dos faces (y no fases necesariamente) diferenciadas de un mismo fenómeno general (el capitalismo multinacional), que tiene obvios alcances culturales (la posmodernidad) y socioeconómicos (el neoliberalismo). Las faces son dos instancias simultáneas del mismo problema. En tanto plural de faz o rostro, tener dos faces es gozar (o sufrir) de una dualidad sincrónica. Las fases (con s) son más bien dos etapas sucesivas, una tras otra en el tiempo. Es decir, en el Perú, neoliberalismo y posmodernidad se dan juntos y no son consecuencia uno de la otra, sino que se alimentan mutuamente al mismo tiempo. En esa línea, un acercamiento ilustrativo es el que ofrece Jorge Larraín en su libro Modernidad, razón e identidad en América Latina, en el cual señala que

el discurso posmoderno no actúa como la vieja ideología liberal, diciéndole a la gente que en el mercado hay libertad, igualdad y propiedad para todos. Más bien le dice a la gente que hay caos en la realidad (escondiendo cuidadosamente el hecho de que ese caos es producido por las mismas fuerzas del mercado) y dislocación a nivel personal, y que nada se puede hacer frente a esto. Por eso es posible sostener que el posmodernismo se ha transformado en la lógica filosófica del neoliberalismo, así como el neoliberalismo se ha convertido en la lógica económica de la modernidad tardía (249-250).

En mi opinión, la gran trampa de un sector considerable del llamado pensamiento neoliberal (como el caso del politólogo estadounidense Francis Fukuyama) es dar partida de defunción a los grandes metarrelatos de la modernidad para imponer el gran metarrelato de la posmodernidad 
neoliberal, la etapa actual del capitalismo caracterizado por la apertura a la inversión extranjera, el fomento de las exportaciones dentro de la globalización, el desmantelamiento de los Estados nacionales como fuerzas de resistencia al influjo avasallador del sistema corporativo internacional, y la pérdida de confianza en los grandes proyectos de transformación social. Dicho "gran metarrelato» lamentablemente se ha convertido en sentido común, al extremo de haber llevado a millones de personas en el mundo a pensar que no existen alternativas al modelo actual. De ahí que Slavoj Žižek,en su libro Visión de paralaje, se refiera a la falta de respuestas políticas efectivas al orden neoliberal transnacional que se vive hoy en la gran mayoría de países del mundo. Žižek busca llamar la atención a los aspectos culturales e ideológicos de los nuevos movimientos ecológicos y etnicistas como formas de compensación relativa, más que de oposición, del sistema neoliberal mundial (448-449). Sin embargo, cabe recordar que en Sudamérica algunos de esos movimientos, como el Katarismo y la Federación de Cocaleros en Bolivia, o el Movimiento Pachakuti en Ecuador, han sido capaces de desestabilizar a diversos gobiernos para colocar, a través de las mismas reglas de la democracia formal, regímenes proindígenas de corte socialista, como los de Evo Morales y Rafael Correa, ambos actualmente en el poder.

Ahora bien, es necesario enfocar la mirada hacia el discurso de la posmodernidad como ideología y como expresión cultural. Como se sabe, tanto el liberalismo como el socialismo son narrativas progresivas de la historia; es decir, conciben la sociedad humana en un curso hacia la amplificación de las posibilidades de su existencia en un devenir lineal y cancelatorio del pasado bajo la lógica consciente con su certeza epistemológica. Son ambos proyectos modernizantes porque buscan superar las antiguas estructuras sociales, políticas y económicas de la sociedad estamental del ancien régime. Las narrativas modernizadoras asumen una racionalidad humana como eje central de la concepción social y priorizan la subjetividad dominante «racional» sobre las subjetividades minoritarias y marginales, tratando de asimilarlas al proyecto nacional-estatal de sus respectivos países. Si las narrativas modernizadoras buscan asimilar las subjetividades subalternas a un proyecto nacional-estatal dominante, en 1979 Lyotard, en La condición postmoderna, hará notar que dicho proyecto era, ad portas de la década de 1980, francamente inconducente.

No obstante, como hace notar Perry Anderson en Los orígenes de la postmodernidad, si bien en dicho libro el filósofo francés anunciaba «el eclipse de todos los grandes relatos», se «empeñaba en certificar por encima de todo» la «muerte» del relato que daba sustento al «socialismo clásico»; énfasis que puede leerse en sintonía con el neoliberalismo que 
empezó su ascenso hegemónico por aquellos días. De ahí que no resulte gratuito lo que señala a su vez Perry Anderson: aunque Lyotard estaba escribiendo hacia al final de «un periodo de seria recesión que distaba mucho de ser entusiasta», es decir, en la denominada era Carter (19771981), el «abrupto cambio de coyuntura de los años 80» vino de la mano de la «euforia» provocada por el boom de la era Reagan y la «triunfal contraofensiva ideológica de la derecha, que culminaría con el derrumbe del bloque soviético a finales de esa década» (47-48). Es debido a este boom que los años 80 significan para Latinoamérica la entrada inicial pero sostenida de la posmodernidad promovida por Estados Unidos y sus aliados.

Esta identificación política de dicha expresión cultural (ligada al consumo y comercialización de mercancías) nos indica que, lejos de haber desaparecido los denominados grandes relatos, lo que se instaló fue la impresión de que por primera vez en su historia el mundo se sometía al dominio de uno de ellos: el relato universal de libertad y prosperidad y de la victoria global del mercado, dentro del cual la posmodernidad se posiciona sobre la condena de las ilusiones alternativas. En resumen, sobre la base de esa condena, y en cuanto a la subrayada declaración política (diversas estrategias, amplitud contestataria) de las manifestaciones estéticas de la posmodernidad periférica, es posible entender la poesía de los autores aquí nombrados como parte de una tendencia creciente por incorporar temporalidades y conciencias diversas, fraccionamientos de la expresión, rupturas de la lógica lineal del poema. Los seis poetas usan en sus textos una serie de elementos epistemológicos y vivenciales que en varios sentidos guarda relación con algunas peculiaridades del pensamiento posmoderno; a saber: el no indagar verdades más allá de los límites del lenguaje, puesto que la verdad no reside sino en las propias correlaciones que el lenguaje del hombre engendra; o el acentuar el carácter llanamente especular de los significados y las imágenes. Este carácter origina la lógica de conocimiento asentada en las expresiones del pastiche, pero también de la parodia crítica que para Linda Hutcheon (4-17) permite expresar una concurrencia de conciencias históricas que desafían la confianza en los homogeneizantes proyectos modernizadores, neoliberal y comunista encarnizadamente enfrentados para el caso de la violencia política. En ese sentido, en tanto un tipo particular de discurso, la poesía de estos autores se resiste a las prácticas neoliberales, pero a su vez está permeada de la estética posmoderna. Esto quiere decir que la tensión entre identidad, estética y posmodernidad tiene un carácter dinámico (nada se mantiene puro), lo cual produce un complejo tejido intercultural donde las identidades culturales y los signos de modernidad se oponen y se fusionan de múltiples y contradictorias formas. 
Terry Eagleton, siguiendo a Gramsci, define la hegemonía «como la variedad de estrategias políticas por medio de las cuales el poder dominante obtiene el consentimiento a su dominio de aquellos a los que domina» (156). Es decir, no basa su poder exclusivamente en los aparatos represivos e ideológicos del Estado, sino que se plantea dentro de la búsqueda y necesidad de consenso, aspecto clave de la hegemonía. Así, esa «variedad de estrategias políticas» para aceptar el consentimiento no es represiva, es permeable y adopta rostros distintos. En tal sentido, esta propuesta calza con una situación como la peruana de la guerra interna, en que la complejidad étnica de la sociedad peruana ha tendido a alinear históricamente a aquellos sectores que guardan una relación de herencia cultural con sus ancestros (reales o no) de origen europeo, en desventaja de los sectores de estirpe quechua o aimarahablante que durante siglos han permanecido bajo distintas formas de dominación. El criollismo hegemónico se basa, de esa manera, en una rearticulación de sus bases socioeconómicas desde tiempos coloniales hasta las distintas fases del periodo republicano, en que la dominación efectiva de las masas indígenas y mestizas pasa (como en los luctuosos años de 1980 a1992) por la represión brutal ejercida desde el propio Estado.

Aquí resulta apropiado observar otro aspecto que apoya lo anterior, y que acerca el concepto de hegemonía a las nociones de mercado, neoliberalismo y posmodernidad. En su artículo «Identidad, comunicación y modernidad en América Latina», Jesús Martín-Barbero afirma que las políticas neoliberales, «al buscar la sustitución del Estado como agente constructor de hegemonía», hacen que la iniciativa privada aparezca como «la verdadera defensora de la libertad de creación y el único enlace entre las culturas nacionales y la cultura internacional, irremediablemente convertida en modelo y guía de la renovación» (105). Se trata de un «desplazamiento del eje de la sociedad», de la política al mercado, que implica «un profundo trastorno, una reconstitución de las identidades, esto es, de los sistemas de reconocimiento y diferenciación simbólica de las clases y los grupos sociales» (105). Este desplazamiento guarda relación con el proceso inicial de la violencia política, cuando el Perú pasó del desmantelamiento del proyecto velasquista de unificación y asimilación de las masas campesinas en un Estado moderno de nacionalismo extremo (1968-1975) al naciente ingreso de la mundialización económica con la segunda fase del gobierno militar (1975-1980) y la reincorporación de la práctica democrática y constitucional a partir de 1980. De este modo, tal reconstitución consiguió resignificar «los conocimientos y hábitos» de la sociedad con su consiguiente «subordinación al complejo sistema transnacional» (106). Así, lo que se logró fue la racionalidad del proyecto 
neoliberal en el «movimiento de segmentación e integración de la economía mundial» (106), rearticulándose los dispositivos del eje colonizador/ colonizado dentro del colonialismo interno, con la prevalencia renovada de los sectores criollos. Este significativo aspecto subrayado por MartínBarbero me permite abordar el complejo concepto de sujeto poético descentrado, que aquí evoco para nombrar las nuevas tonalidades que se dejan percibir en los poemas de estos seis autores escindidos entre las rearticulaciones operadas bajo el fuego cruzado de la violencia política. Es, pues, una postura distante y crítica al sujeto centrado de la modernidad (sujeto racional, prefreudiano, de la llustración).

A través de la interpelación tanto el discurso fundamentalista senderista como el discurso neoliberal del autoritarismo militar o del discurso del mercado configuran a sus sujetos dentro del marco de su ideal de nación, encerrándolo en una única posición subjetiva (la del «sujeto de la guerra revolucionaria» o el «sujeto libre» para cada caso). Como ya indiqué páginas arriba, los seis poetas buscan desmarcarse de todo aquello. En oposición al sujeto unitario (constituido objetivamente en la subjetividad), que en su pretensión de unidad busca una respuesta englobante, lógica, definitiva a los conflictos y orientada hacia la búsqueda de una visión abarcadora, la figura del sujeto poético descentrado ante el devenir de la historia en una época convulsionada como el de la violencia política se mueve por territorios movedizos, poco firmes. En el Perú, ese sujeto poético descentrado parecería originarse en los años 60 , aunque con serias limitaciones. Este origen coincide con la renovación estética en la poesía peruana a cargo de autores canónicos como Antonio Cisneros, Rodolfo Hinostroza o Luis Hernández. Cabe adelantar, sin embargo, que el lenguaje poético del circuito dominante en español en el Perú adquiere características definidas en los años 60 a partir de la difusión de dos grandes vertientes de la poesía latinoamericana: el exteriorismo y la antipoesía. Si bien ambas corrientes (representadas respectivamente por voces mayores como las de Ernesto Cardenal en Nicaragua y Nicanor Parra en Chile) ya tenían antecedentes claros en la denominada otra vanguardia de estirpe anglosajona, según la llama José Emilio Pacheco, en el Perú y en otras tradiciones poéticas «oficiales» o criollas de América Latina coincide con un entusiasmo evidente por un orden social progresivo, basado en el socialismo (es el caso de Cisneros, por ejemplo) o en la crítica del capitalismo desde una visión beat y contestataria (como en Hinostroza).

La fragmentación del sujeto poético de estos poetas del 80 no se agota en la tensión de los universos culturales: invade todos los espacios de su experiencia, pero también la manera particular de concebir el lenguaje, al plantear una disipación de las fronteras entre lenguaje literario y lenguaje 
cotidiano. De ese modo, en los seis poetas nombrados la alteridad cultural no entra solamente como representación, sino que también se inserta como escritura: la otredad se incrusta en la escritura. El sujeto descentrado no solo se da en la oposición antes señalada; también está relacionado con las oposiciones entre centro y periferia, urbe y campo, clase alta y clase baja, etcétera. Esta suma de oposiciones, radicalmente confrontadas durante la violencia política, permite el protagonismo y la hegemonización que el sujeto poético descentrado adquiere en la poesía peruana durante dicho periodo. Por ello, estos autores no correspondan al sujeto militante revolucionario propio de los años 60 y 70 en América Latina. En ese sentido, subrayemos, ese descentramiento pasa a su vez por la no correspondencia con el «sujeto de la guerra revolucionaria» propugnado en el Perú de los 80 por el maoísmo senderista; modelo de sujeto que sin embargo no se mantuvo ajeno al ámbito de la producción poética, como lo atestiguan los casos de Jovaldo (1951-1986) y Edith Lagos (1962-1982).

En resumidas cuentas, el neoliberalismo en el Perú empieza con Morales Bermúdez (así como en Chile con Pinochet y en Argentina con Videla), y muestra desde su origen la entraña fascista del modelo económico y político que ha primado en América Latina en los últimos treinta años. Negar la existencia del neoliberalismo en los 80 es ocultar una parte fundamental del contexto en que los jóvenes poetas de entonces empezaron a expresar su rechazo al sistema político y económico que les tocó al inicio de su vida adulta. Por eso, una valoración de la producción poética de aquellos años en función de sus coordenadas internacionales nos llevará a una comprensión más amplia e interdisciplinaria del fenómeno poético «culto» en el Perú. 


\section{REFERENCIAS BIBLIOGRÁFICAS}

ANDERSON, Perry (2000). Los orígenes de la postmodernidad. Barcelona: Anagrama.

(2003). «Balance del neoliberalismo: lecciones para la izquierda». En Revista de Crítica Cultural, nro. 26.

CHIRINOS, Eduardo (1981). Cuadernos de Horacio Morell. Lima: Trompa de Eustaquio.

(1984). Crónicas de un ocioso. Lima: Trompa de Eusta-

quio.

(1985). Archivo de huellas digitales. Lima: Copé.

(1989). Canciones del herrero del arca. Lima: Colmillo

Blanco.

CRISTÓBAL, Juan; RONCAL, Jorge Luis, y VALCÁRCEL, Rosina (editores) (1998). Di tu palabra: 9 poetas alzadas. Lima: Arteidea.

DE RAMOS, Domingo (1988). Arquitectura del espanto. Lima: Asaltoalcielo. (1993). Pastor de perros. Lima: Asaltoalcielo y Colmillo

Blanco.

EAGLETON, Terry (1997). Ideología. Una introducción. Barcelona: Paidós.

FOUCAULT, Michel (2007). Nacimiento de la biopolítica. Buenos Aires: Fondo de Cultura Económica.

FUKUYAMA, Francis (1992). The End of History and the Last Man. Nueva York: Avon Books.

GRAMSCl, Antonio (1992). Prison Notebooks. Nueva York: Columbia University Press.

HUTCHEON, Linda (1989). The Politics of Postmodernism. Nueva York y Londres: Routledge.

JOVALDO [José Valdivia Domínguez] (2005). Canto al futuro. Poemas inéditos. Lima: Ediciones Kusikusum.

LARRAÍN IBÁÑEZ, Jorge (1996). Modernidad, razón e identidad en América Latina. Santiago: Editorial Andrés Bello.

LYOTARD, Jean-François (2000). La condición postmoderna. Madrid: Cátedra.

MARTÍN-BARBERO, Jesús (1994). «Identidad, comunicación y modernidad en América Latina». En Hermann Herlinghaus y Monika Walter (editores). Postmodernidad en la periferia. Enfoques latinoamericanos de la nueva teoría cultural. Berlín: Langer Verlag. 
MATOS MAR, José (2004). Desborde popular y crisis del Estado. Veinte años después. Lima: Fondo Editorial del Congreso del Perú.

MAZZOTTI, José Antonio (1981). Poemas no recogidos en libro. Lima: Federación Universitaria de San Marcos.

y Orellana, Consorcio Editorial.

(1985). Fierro curvo. Lima:Trompa de Eustaquio, Kloaka (1991). Castillo de popa. Lima: Asaltoalcielo.

(1999). El zorro y la luna. Antología poética 1981-1999. Lima: Fondo Editorial del Banco Central de Reserva del Perú.

MENDIZÁBAL, Raúl (1995). Dedeálade (poemas y canciones). Filadelfia: Asaltoalcielo. quio, Asaltoalcielo e Hipocampo.

(2004). Dedeálade. 69 poemas. Lima: Trompa de Eusta-

ORIHUELA, Carlos L. (2006). «La poesía peruana de los 60 y 70: Dos etapas en la ruta hacia el sujeto descentrado y la conversacionalidad». En A Contracorriente, nro. 1.

PACHECO, José Emilio (1979). «Notas sobre la otra vanguardia». En Revista Iberoamericana, nro. 45.

RUIZ-ROSAS, Dalmacia (1998). Secuestro en el jardín de las rosas. Lima: Hipocampo.

(2000). Baile. Lima: Hipocampo.

(2006). Conjunto de objetos encontrados — detestables sentimientos de jóvenes ingeniosos-. Lima: Hipocampo.

SANTIVÁÑEZ, Róger (1979). Antes de la muerte. Lima: Cuadernos del Hipocampo.

(1984). Homenaje para iniciados. Lima: Reyes en el Caos. (1988). El chico que se declaraba con la mirada. Lima:

Asaltoalcielo.

(1991). Symbol. Princeton: Asaltoalcielo.

(1995). Cor cordium. Amherst: Asaltoalcielo.

(2006). Dolores Morales de Santiváñez (Selección de poesía 1975-2005). Lima: Hipocampo y Asaltoalcielo.

ŽlŽEK, Slavoj (2006). Visión de paralaje. Buenos Aires: Fondo de Cultura Económica. 